\title{
Control of Welding Residual Stress for Dissimilar Laser Welded
}

\author{
Materials \\ E. M. Anawa and A. G. Olabi \\ School of Mechanical \& Manufacturing Eng., Dublin City University, Dublin 9, Ireland \\ ezzeddin.hassan2@mail.dcu.ie, abdul.olabi@dcu.ie
}

\begin{abstract}
The most common problem of welding dissimilar metals (DMWs) with respect to residual stresses is the differences in the coefficient of thermal expansion and heat conductivity of the two welded metals. In the present work, a $\mathrm{CO}_{2}$ continuous laser welding process was successfully applied and optimized for joining a dissimilar AISI 316 stainless steel and low carbon steel plates.

The Taguchi approach with three factors (selected welding parameters) at five levels each (L3-25) was applied to find out the optimum levels of welding speed, laser power and focal position for $\mathrm{CO}_{2}$ keyhole laser welding of dissimilar butt weld. The responses outputs were the residual stresses at different depth in the heat affected zone (HAZ). The Hole-Drilling Method technique was applied to measure the residual stress of dissimilar welded components. The results were analysed using analysis of variances (ANOVA) and signal-to-noise ratios $(\mathrm{S} / \mathrm{N})$ for an effective parameters combination. Statistical models were developed to describe the influence of the input parameters on the residual stress at different specimen levels; to predict there value within the limits of
\end{abstract}


the variables under investigation. The result indicates that the developed models can predict the responses satisfactorily.

Keywords: Residual stresses, Hole-Drilling Method, Dissimilar welding, Taguchi approach.

\section{INTRODUCTION}

Welding of metals and alloys is an experienced subject, dissimilar welding represents a major scientific and technical challenge. Emerging new technologies increasingly require dissimilar metals and alloys to be joined. Laser processing is free of electromagnetic fields which may leads to missed joints in dissimilar components such as Ni-Cu, Sun, (1996) and is, thus, suitable for welding dissimilar components. With flexibility in the power intensity, power distribution, and scanning velocity, laser welding is emerging as a major joining process Sun, (1999). One of the most critical problems associated with joining dissimilar materials is the formation of residual stresses. The internal state of stress is caused by thermal and/or mechanical processing of the parts. Common examples of these are bending, rolling or forging a part. Another example is the thermal stresses induced as a result of welding. Residual stresses can result in visible distortion of a component. Residual stress is one of the most important factors, that affect fatigue strength and it is well known that residual stress is more of a concern for high-cycle fatigue than the other factors. Residual stress control during the welding process can easily protect welded components without any additional procedure after welding. The distortion can be useful in estimating the magnitude or direction of the residual stresses Mochizuki M., (2007). In this study dissimilar metal weld (DMW) 
refers to a weld joining two materials from different alloying compositions. The residual stress problem is arising due to the heat absorbed during the welding process and is dramatically complicated when subjected to differences in the coefficient of thermal expansion and thermal conductivity between the welded components. Austenitic stainless steel used in this study has a thermal conductivity of one third of carbon steel. The austenitic stainless steel grades have a 50\% greater thermal expansion than carbon steels and coupled with a lower thermal conductivity, are prone to unequal expansion and distortion when they are joined together Dawes, (1992). High value of residual stress would be concentrated in HAZ due to the expansion resulted by phase change during cooling Masabutchi, (1980). Therefore higher residual stresses occur in the HAZ in the stainless steel side of Ferritic/ Austenitic (F/A) joints.

Design of Experiments (DOE) and statistical techniques are widely used to optimize process parameters. Anawa and Olabi, (2006) were applied the DOE and Taguchi techniques to study the effect of laser welding conditions on toughness of dissimilar welded components. Roy, 2001; Tarng et al. (2002) were conducted study to identify the optimal process input parameters using of grey-based Taguchi methods to determine submerged arc welding process parameters. The DOE technique using the Taguchi approach can economically satisfy the needs of problem solving and product/process design optimization projects in the manufacturing industry. The application of DOE requires careful planning, prudent layout of the experiment, and expert analysis of results. Based on years of research and applications, Dr. Genichi Taguchi has standardized methods for each of these DOE application steps. Thus, DOE using the Taguchi approach has become a much more attractive tool to practicing 
engineers and scientists. Anawa and Olabi, (2008) have used Taguchi parameter 'design robust design', as an optimization approach that uses a series of experiments (computerbased or physical) to find parameter settings for the design that yield predicted performance to be on target and as insensitive to noise as possible.

This work aims to control and optimize selected laser welding parameters by applying the Taguchi method and ANOVA analysis to minimize the residual stresses (responses) in the dissimilar welded components, in particular in the heat affected zone (HAZ) and to develop a statistical model to predict and optimize the residual stresses in the design stage. The effect of individual welding parameter on the residual stress also has been investigated in this study.

\section{EXPERIMENTAL DESIGN}

An L3-25 Taguchi orthogonal array design was applied which comprised of 3 columns and 25 rows result in 25 experiments that were carried out. Design selection was based on three welding parameters at five levels each. The selected welding parameters for this study are: welding power $(\mathrm{P})$, welding speed $\left(\mathrm{S}_{\mathrm{w}}\right)$ and focus point position $(\mathrm{F})$. Table 1 show the laser input variables and experiment design levels. The Taguchi method was applied to the experimental in a random order to avoid any systematic error in the experiment data using statistical software "Design-Expert 7" and "MINITAB 13". Usually, there are three categories for the quality characteristic in the analysis of the $\mathrm{S} / \mathrm{N}$ ratio, (lower-the-better, the higher-the-better and the nominal-thebetter). The $\mathrm{S} / \mathrm{N}$ ratio for each rank of process parameters is computed based on the $\mathrm{S} / \mathrm{N}$ analysis. Referring to the category of the quality characteristic, a lower $\mathrm{S} / \mathrm{N}$ ratio 
corresponds to a better quality characteristic. Therefore, the optimal rank of the process parameters is the rank with the lowest $\mathrm{S} / \mathrm{N}$ ratio.

Furthermore, statistical ANOVA is performed for the responses to see which process parameters are statistically significant. The purpose of the ANOVA is to investigate which welding process parameters significantly affect the quality characteristic. This is accomplished by separating the total variability of the $\mathrm{S} / \mathrm{N}$ ratios, which is measured by the sum of the squared deviations from the total mean of the $\mathrm{S} / \mathrm{N}$ ratio, into contributions by each welding process parameter and the error Juang and Tarng (2002), the optimal combination of the process parameters can then be predicted.

\section{EXPERIMENTAL PROCEDURE}

The materials employed in this investigation were plates of AISI 316 stainless steel and AISI 1008 low carbon steel with dimensions of $160 \mathrm{~mm}$ x $80 \mathrm{~mm}$ x $2 \mathrm{~mm}$ each and were butt welded to produce the dissimilar welded joint. The typical chemical compositions and the mechanical properties of the received materials are shown in Table 2 and Table 3 respectively. The joints were produced using continues $\mathrm{CO}_{2}$ laser beam welding machine at a maximum laser power capacity of $1.5[\mathrm{~kW}]$. The plates were tightly clamped during joining process to avoid any thermal deformation caused by the heat input, which may affect the responses. Visual inspection of welding defects and full depth of penetrations were the criteria for determining the working ranges. Welding seem of a selected produced joints is exhibited in Fig.1a and Fig. 1b (face and bottom) of the specimens respectively. The welding operation was accomplished according to the 
design matrix Table 5 in a random order to avoid any systematic error in the experiment. Argon gas was used as shielding gas at constant flow rate of 5 [1t/min] with welding conditions range as described in Table 1.

The most widely used practical technique for measuring residual stresses is the hole-drilling strain gage method described as a semi destructive which allows measuring the stress gradient in the depth of the material. This technique is a stress-relaxing method which analysis the stress-relaxation created in a metal part when material is removed, Viotti et. al, (2006). With this method, a specially configured electrical resistance strain gage rosette is bonded to the surface of the test object, and a small shallow hole is drilled through the centre of the rosette. The local changes in strain due to an introduction of the hole are measured, and the relaxed residual stresses are computed from these measurements. Although there are a number of possible error sources like; gage drift and poor soldering, human errors in milling the holes associated with the hole drill method application but so far it is the only method for measurement of residual stresses that is accepted as an ASTM standard. The practicality and accuracy of this method is directly related to the precision with which the hole is drilled through the centre of the strain gage rosette (Schajer G.S., 1981; Vishay Measurements group, 2007).

The basic test procedure described in measurement group TN-502-5 conducted by Lu, (1996), was followed Strain Gauge Rosette of type CEA-06-062UM- 120 was chosen because it was necessary to measure stresses as close as possible to the weld pool area. The strain gauge was bonded to the surface of the specimen (stainless-steel side) in the HAZ were the present of the critical (serious) residual stresses in the joined component and a blind hole of incremental depth of $1.524 \mathrm{~mm}$ was drilled at 2-3 mm 
from the center welded line in the middle of the specimen as presented in Fig.2. In this work, the RS-200 Milling Guide device with an ultra-high speed air turbine and a carbide cutter of diameter $1.6 \mathrm{~mm}$ were used. Calibration coefficients $\bar{a}$ and $\bar{b}$ for 062UM rosette (for blind holes) for all the depth levels were calculated and obtained using a special graph developed by Nickola, (1986). The micro-strains $(\varepsilon)$ at different depth levels were measured and used to calculate the principal residual stresses. The principal residual stresses were calculated at each level using the following equations:

$\sigma_{\min }, \sigma_{\max }=\frac{\varepsilon_{3}+\varepsilon_{1}}{4 \bar{A}} \pm \frac{\sqrt{\left(\varepsilon_{3}-\varepsilon_{1}\right)^{2}+\left(\varepsilon_{3}+\varepsilon_{1}-2 \varepsilon_{2}\right)^{2}}}{4 \bar{B}}$

Where: $\bar{A}=-\frac{1+v}{2 E} \times \bar{a} \quad$ and $\quad \bar{B}=-\frac{1}{2 E} \times \bar{b}$

Depth levels at which the micro-strains were measured are presented in Table 4. The calculated stress $(\sigma)$ at each level expressed in Table 5, were considered as responses and analyzed separately to predict the effect of the welding parameters through specimen depth.

\section{RESULT AND DISCUSSION}

Residual stress were studied and analyzed through the depth of the welded joint at gradual levels to get a clear indication of the effect of welding parameters on the distribution of the residual stress through the depth of HAZ and to optimize it. "Design 
Expert 7" software has been used for analysing the measured responses. The fit summary output indicates that the models developed are statistically significant for the prediction of the responses therefore they will be used for further analysis. From the obtained results, it can be seen that the residual stresses are controlled by the rate of heat input, which is a function of laser power and welding speed. However, the focusing parameter has limited affect to the residual stress, especially at certain levels Anawa and Olabi, (2007) and as indicated in the models developed in this study.

\subsection{The $\mathrm{S} / \mathrm{N}$ ratio Analysis}

In order to evaluate the influence of each selected parameter on the responses: the $\mathrm{S} / \mathrm{N}$ for each control factor had been calculated for each level separately. The signals have indicated that the effect on the average responses and the noises were measured by the influence on the deviations from the average responses, which would indicate the sensitivity of the experiment output to the noise factors. The appropriate $\mathrm{S} / \mathrm{N}$ ratio must be chosen using previous knowledge, expertise, and understanding of the process. When the target is fixed and there is a trivial or absent signal factor (static design), it is possible to choose the $\mathrm{S} / \mathrm{N}$ ratio depending on the goal of the design. In this study, the $\mathrm{S} / \mathrm{N}$ ratio was chosen according to the criterion the-smaller-the-better, in order to minimize the responses. The $\mathrm{S} / \mathrm{N}$ ratio for the-smaller-the-better target was calculated as follows:

$$
M S D=\left(Y^{2}{ }_{1}+Y^{2}{ }_{2}+\ldots \ldots \ldots \ldots \ldots \ldots . . . .+Y^{2}{ }_{n}\right) / n \quad \text { for smaller is better }
$$


Where: $\mathrm{y}$ is the average measured residual stresses, $\mathrm{n}$ is equal to the number of repetitions, in this study $n=25$

For the first response which was considered as the residual stresses at level 1, in the specimen, the data in Table 5 with the above formulas (2 and 3) were used for calculating S/N, while the Taguchi experiment results are presented in Fig. 3, which was obtained by using of MINITAB 13 statistical software. The same procedure were applied for other responses for the levels from 2 to 7 which are expressed in Table 4 for calculating $\mathrm{S} / \mathrm{N}$ and presented in Fig. 4-9. The effects of welding parameters vary between various depth levels. The welding parameters on all the levels by means of S/N ratio are summarized and presented in Fig. 10. From this Figs. illustration, it's clear that the welding speed has the strongest effect on the process by means of residual stresses.

\subsection{The ANOVA Analysis}

Farther investigations for welding process parameters were carried out, using ANOVA, to identify which parameter is significantly affecting the welding quality. This is accomplished by separating the total variability of the $\mathrm{S} / \mathrm{N}$ ratios, which is measured by the sum of the squared deviations from the total mean of the $\mathrm{S} / \mathrm{N}$ ratio, into contributions by each welding process parameter and the error [21]. The test for significance of the regression model, the test for significance on individual model coefficients and the lack-of-fit test were performed using Design Expert 7 software. Step-wise regression method; which eliminates the insignificant model terms automatically was applied for each level and exhibited in ANOVA Tables 6-12 for the 
models. ANOVA Tables summarise the analysis of the variances of the responses and show the significant models. The same tables show also the other adequacy measures $R^{2}$, adjusted $R^{2}$, and adequacy precision for each response. The adequate precision compares the range of the predicted value at the design points to the average predicted error. An adequate precision ratio above 4 indicates adequate model discrimination. In this study the values of adequate precision for all models developed were significantly greater than 4. All the adequacy measures in all ANOVA Tables indicate that adequate models have been obtained. The final mathematical models in terms of actual factors as determined by design expert software are shown below.

$$
\begin{aligned}
& \sigma_{1}=332.619-0.188 * S w \\
& \sigma_{2} \quad=146.525+66.030 * P-0.134 * S w \\
& \sigma_{3} \quad=166.686-0.093 * S w
\end{aligned}
$$

$$
\begin{aligned}
\sigma_{4}= & 2607.557-3593.719 * P-4.217 * S w-50.207 * F \\
& +4.735 * P * S w-0.028 * S w * F+1456.648 * P^{2} \\
& +1.7 E-003 * S w^{2}-168.087 * F^{2}-1.916 * P^{2} * S w \\
& -7.7 E-007 * S w^{3}-92.056 *
\end{aligned}
$$

$\sigma_{5}=281.134-252.328 * P-0.074 * S w+38.307 * F$ 


$$
\begin{aligned}
- & 0.048 * S w * F+103.223 * P^{2} \\
\sigma_{6} \quad= & 81.256+15.872 * P-0.043 * S w \\
\sigma_{7} \quad= & -2806.843+7244.767 * P-0.038 * S w-15.499 * F \\
& -5999.662 * P^{2}-17.386 * F^{2}+1645.974 * P^{3}
\end{aligned}
$$

\section{EFFECT OF THE PARAMETERS ON THE PROCESS}

The reason for predicting the residual stresses is to develop a model to control and to optimize them by controlling the welding parameters. Figs. $11-17$ present 3D graphs of the effect of $\mathrm{S}_{\mathrm{w}}, \mathrm{P}$ and $\mathrm{F}$ on the response at each depth level.

At level 1 of the specimen depth, the analysis of variance presented in Fig. 11 and expressed in Table 6, indicates that the main effect on the residual stresses is the welding speed $S_{\mathrm{w}}$ as presented in Fig. 3; while the other parameters had an insignificant effect on the response. The analysis indicates also that the model developed was significant with an Adequate Precision of 9. Since depth level 1 is nearest to the specimen surface and the cooling rate is very fast; the response has the highest value at this level. The maximum response value was at experiment number 16 at $320[\mathrm{MPa}]$ and the lowest value was obtained at experiment number 5 at $142[\mathrm{MPa}$. The wide range of responses at all experiment settings (142- $320[\mathrm{MPa}])$ reflects the strong effects of welding parameters on the process. 
At level 2 of the specimen depth, the analysis of variance presented in Fig.12 and expressed in Table 7, indicates that the response is affected by laser power and welding speed. At this depth level, the model developed was significant and the Adequate Precision was 15. R2 and Adjusted R2 values emphasise the significance of the model developed. It indicates that depth level 2 is deeper than depth level1 due to the slower cooling rate, which result in lower response ranges (between 202 and 82 [MPa]) as expressed in Table 5 and presented in Fig. 4.

The ANOVA analysis presented in Fig. 13 and expressed in Table 8 for depth at level 3 indicates that the model developed was significant. At this depth level, only the welding speed parameter affected the response. The response values were further decreased in comparison to the upper depth levels and had its min and maximum values at experiments numbers 5 and 16 respectively.

The model at depth level 4 is very complicated and is presented in Fig. 14. Since this level is located at the centre depth of the specimen, where the cooling rate will occur at both specimen sides at different rates; the resulting model is complex. At this depth level all the considered welding parameters had an effect on the response. At this depth level, second and third order parameters effects were observed. Interaction effects between welding speed / laser power and between welding speed / focus position are also included in the model at this depth level. The ANOVA analysis, expressed in Table 9 indicates that the model is significant. Penetrating deeper in to the specimen; the residual stress resulting due to welding operation decreases and this is presented in the above two depth levels whereby the response has decreased. Higher and lower values of 
this response were observed at experiments conducted at depth levels in experiments 5 and 16.

The model developed at a specimen depth of level 5 is statistically analysed and presented in Fig. 15 and expressed in Table 10, which indicate that the model is significant. The ANOVA analysis expressed in Table 10 indicates that all welding parameters have an affect the response at this depth level. The possibility for second order effects of laser power is presented and an interaction effect between (welding speed and focus position) is accounted for the model developed. The response was further decreased in comparison to superficial depth levels and the range between the max and min response values was found to decrease. The range of values of this response varied between experiments numbers 4 and 16.

At depth level 6; the developed model was analysed. The ANOVA is expressed in Table 11 and indicates that the model is significant. The laser power and welding speed parameters are found to affect the model while focus position has no significant effect as shown in Fig. 8. The maximum response was observed at experiment number 16 at 79 $[\mathrm{MPa}]$ and the minimum were observed at experiment number 5 at $50[\mathrm{MPa}]$, as is presented in Fig. 16.

Similarly, the model developed at depth level 7and presented in Fig. 17, was analysed and is expressed in Table 12 which indicates that the model is significant and is affected by all welding parameters. Second order of laser power, focus position and third order of laser power are also found to affect the response. At this depth level, the maximum response value differed in comparison to all the other superficial levels (at the experiment number 23) while the minimum response value was similar to all other depth 
levels at experiment number 5 . This is an account of the depth level being far way from the serves and the heat source has a negligible affect on the welding process. Also the response range has the smallest changing range in all experiment settings (76 - 5 [MPa]). In all the above models, it is clear that the welding speed was the most significant parameter in the process, while the effect of the laser power and focus position factors were lower and varied between each depth level.

\section{CONCLUSION}

The following points can be concluded from this study:

1. Laser welding can be applied successfully for joining dissimilar F/A steels.

2. The optimization technique would result in the lower residual stresses and the narrow HAZ.

3. Welding speed has the strongest effect on the residual stresses among the studied parameters, e.g. increasing weld speed decreses residual stresses.

4. Laser power has strong effect on the residual stress. By changing the laser power the residual stresses are changed dramatically. This can be considered as the optimum setting with respect to residual stresses. The $\mathrm{P}$ value should be carefully selected. While the focusing position parameter has an insignificant effect on the total residual stresses.

5. The welding parameters setting at experiment number fife gives the minimum residual stresses for all the levels of specimen. This can be considered as the optimum settings with respect to residual stresses. 
6. The range of the parameters should be carefully selected to give the acceptable full penetration and sound weld for all combinations of experiment runs. The models developed can be rounded to adequately predict the residual stress within the factors domain investigated.

\section{Acknowledgement}

Libyan ministry of higher educational is gratefully acknowledged for the financial support of this research. Technical support from Mr. Martin Johnson, Mr. Michael May and Dublin City University are also gratefully acknowledged.

\section{REFERANCES}

Anawa E.M. and Olabi A.G., 2006, Effect of laser welding conditions on toughness of dissimilar welded components, J. of Applied Mechanics and Materials, Vol. 5-6, pp. 375-380.

Anawa E.M. and Olabi A.G., ,2007, The Application of The Hole Drilling Method to Define The Residual Stress of Dissimilar Laser Welded Components, J. of Applied Mechanics and Materials, Vol. 7-8, pp. 133-138.

Anawa E.M. and Olabi A.G., 2008, Using Taguchi method to optimize welding pool of dissimilar laser-welded components, Optics \& Laser Technology, J of Optics \& Laser Technology, Vol. 40, pp. 379-388.

Dawes C., 1992, laser Welding, Mc Graw-Hill, Inc, New York.

Juang S.C., Tarng Y.S., 2002, Process parameter selection for optimizing the weld pool geometry in the tungsten inert gas welding of stainless steel, Journal of Materials Processing Technology, Volume 122, Issue 1, pp. 33-37.

Lu J., 1996, Handbook of measurement of residual stresses. Society of Experimental Mechanics Inc, the Fairmont press.

Masabutchi K., 1980, Analysis of Welded Structures, Pragamon Press Ltd.

Mochizuki M.,2007, Control of welding residual stress for ensuring integrity against fatigue and stress-corrosion cracking, Nuclear Engineering and Design, Volume 237, Issue 2, pp. 107-123.

Nickola W. E., 1986, Practical subsurface residual stress evaluation by hole drill method, SEM Conference on Experimental Mechanics, Neew Orleans, pp 47-57. 
Roy R. K., 2001, Design of Experiments Using Taguchi Approach, John Wiley and sons, inc.

Schajer G.S., 1981, Application of Finite Element Calculations to Residual Stress Measurements, Journal of Engineering Materials and Technology volume 103, pp. 157163.

Sun Z., 1996, Feasibility I5of producing ferritic/austenitic dissimilar metal joints by high energy density laser beam process, International Journal of Pressure Vessels and Piping, Volume 68, Issue 2, pp. 153-160.

Sun Z., 1999, M. Kuo, Bridging the joint gap with wire feed laser welding J. of Materials Processing Technology, V. 87, Issues 1-3, pp.213-222.

Tarng Y.S., Juang S.C. and Chang C.H., 2002, The use of grey-based Taguchi methods to determine submerged arc welding process parameters in hardfacing, Journal of Materials Processing Technology, Volume 128, Issues 1-3, pp. 1-6.

Viotti M. R., Dolinko A. E., Galizzi G. E. and Kaufmann G. H., 2006, A portable digital speckle pattern interferometry device to measure residual stresses using the hole drilling technique,, Journa of Optics and Lasers in Engineering, Volume 44, Issue 10, pp. 1052-1.

Vishay measurements_group, 2007. http://www.vishay.com/brands/measurements_group/guide/.htm. 


\section{LIST OF SYMBOLES USED}

P: $\quad$ Laser Power

$\mathrm{S}_{\mathrm{w}}$ : Welding Speed

F: $\quad$ Focus position

HAZ: Heat Affected Zone

$\varepsilon: \quad$ Micro-strains

$\sigma: \quad$ Principal stress

$v: \quad$ Poisson's ratio

E: $\quad$ Elastic Modulus

$\alpha: \quad$ Stress direction

$\bar{a}, \bar{b}$ : Calibration coefficients for 062UM rosette

$\mathrm{R}^{2}$ : $\quad$ A measure of the amount of variation around the mean explained by the model

S/N: Signal-to-noise

F/A: Ferritic/ Austenitic

$\mathrm{F}_{\mathrm{v}}$ : $\quad$ Statistical F-Value

df: Degree of freedom 


\section{List of tables:}

Table 1, Process parameters and design levels used

Table 2, Chemical composition of the materials (wt \%)

Table 3, Mechanical properties of used materials

Table 4, Depth at which the micro-strains were measured in the specimens

Table 5, Experimental assignments with random order and residual stresses

Table 6, ANOVA for residual stress at level 1

Table 7, ANOVA for residual stress at level 2

Table 8, ANOVA for residual stress at level 3

Table 9, ANOVA for residual stress at level 4

Table 10, ANOVA for residual stress at level 5

Table 11, ANOVA for residual stress at level 6

Table 12, ANOVA for residual stress at level 7 


\section{List of figures:}

Fig. 1, Shows the welding seem (a / $\mathrm{b}$ face side and bottom side respectively) of a selected produced dissimilar joints.

Fig. 2, Shows the rosette (Strain Gage not to scale) bonded to the surface of the specimen.

Fig. 3, Main effects plot for response $1 \mathrm{~S} / \mathrm{R}$ ratio.

Fig. 4, Main effects plot for response 2 S/R ratio.

Fig. 5, Main effects plot for response $3 \mathrm{~S} / \mathrm{R}$ ratio.

Fig. 6, Main effects plot for response 4 S/R ratio.

Fig. 7, Main effects plot for response $5 \mathrm{~S} / \mathrm{R}$ ratio.

Fig. 8, Main effects plot for response $6 \mathrm{~S} / \mathrm{R}$ ratio.

Fig. 9, Main effects plot for response $7 \mathrm{~S} / \mathrm{R}$ ratio.

Fig. 10, Shows the average effect of welding parameters on residual stress at HAZ.

Fig. 11, Shows 3-D plot for effected parameters against the residual stress.

Fig. 12, Shows 3-D plot for effected parameters against the residual stress.

Fig. 13, Shows 3-D plot for effected parameters against the residual stress.

Fig. 14, Shows 3-D plot for effected parameters against the residual stress.

Fig. 15, Shows 3-D plot for effected parameters against the residual stress.

Fig. 16, Shows 3-D plot for effected parameters against the residual stress.

Fig. 17, Shows 3-D plot for effected parameters against the residual stress. 